\title{
REVIEW \\ Near-Infrared Spectrometer for a Head-Feeding Combine for Measuring Rice Protein Content
}

\author{
Yasuyuki HIDAKA ${ }^{1 *}$, Eiji KURIHARA ${ }^{1}$, Kazunobu HAYASHI', \\ Takahiro NODA ${ }^{1}$, Yoh NISHIMURA ${ }^{1}$, Takao SUGIYAMA ${ }^{1}$, \\ Kengo MURAMATSU ${ }^{2}$ and Kunio SASHIDA ${ }^{3}$ \\ ${ }^{1}$ Crop Production Machinery and System Department, Bio-oriented Technology Research \\ Advancement Institute (BRAIN), National Agriculture and Food Research Organization (Nisshin, \\ Saitama 331-8537, Japan) \\ ${ }^{2}$ Shizuoka Seiki Co. Ltd. (Fukuroi, Shizuoka 437-1121, Japan) \\ ${ }^{3}$ SOMA OPTICS Co. Ltd. (Nishitama, Tokyo 190-0182, Japan)
}

\begin{abstract}
We have developed a near-infrared (NIR) spectrometer mountable on a head-feeding combine for measuring rice protein in real time while harvesting. The developed sensor employs reflectance optics instead of the more usual transmittance optics because (1) it operates under severe vibration and dust conditions; (2) it performs measurements in high moisture contents, low fluidity of rough rice; and (3) because of low light transmittance due to absorption by husks. The light source was a tungsten halogen lamp, with a diffusion cylinder installed so that uniform light would illuminate the sample. An Si-CCD measured the spectrum from $740 \mathrm{~nm}$ to $1140 \mathrm{~nm}$ with a post-dispersive grating. We made a calibration curve of brown rice protein from a spectrum of rough rice examined in a laboratory. The calibration curve accuracy was $r=0.87$ and SECV (Standard Error of Cross-Validation) $=0.47 \%$. In the adopted measurement method, the sensor loaded the rough rice into a wide sample chamber by gravity and analyzed the loaded grain at the bottom using a reflected signal. The developed sensor was able to measure the protein content of brown rice from spectra of rough rice taken under severe conditions, e.g., a high-vibration, high-dust harvesting environment. In addition to the protein content, the rice weight and moisture content could be displayed on the monitoring terminal in real time. The accuracy of the protein content measurements in these field examinations was $r=0.65$ and SEP (Standard Error of Prediction) $=0.22 \%$. The SEP was far better than the SECV of the calibration, but the protein content fell in a narrow range in the field examination. Thus, we concluded that the actual accuracy was the same as the calibration.
\end{abstract}

Discipline: Agricultural machinery

Additional key words: yield-monitoring combine, precision agriculture

\section{Introduction}

A practical yield-monitoring combine is a necessary tool for precision agriculture. In Japan, yield-monitoring combines were developed by improving the head-feeding combine $^{15}$ and designing a system for field-specific management using information gathered on individual field sections throughout entire districts ${ }^{6}$. These combines were commercialized in 2009 in one of our projects. Once yield and moisture content data can be obtained by a yield-monitoring combine, the next focus of interest is information relating to quality. The protein content of rice has a negative correla- tion with palatability ${ }^{1,14}$. Fertilization is managed at production sites to harvest rice with low protein content. Moreover, low protein content might represent high value. Some $60 \%$ of rice farmers want to be able to check protein content in the field or before drying ${ }^{16}$.

Near-infrared (NIR) sensors for wheat have been developed and mounted on conventional combines, and research is in progress to develop the next stage of sensors for mounting on yield-monitoring combines in Europe, Australia, and the United States. Both transmittance ${ }^{7}$ and reflectance ${ }^{8}$ sensors have been developed, and sensors mounted on the grain-conveying lines of conventional combines were introduced into the market. Taylor et al. ${ }^{20}$ and 
Long et al. ${ }^{11}$ succeeded in measuring wheat protein content as it was being harvested using a conventional combine ( $r=0.67$ to 0.77 and $\mathrm{SEP}=0.65$ to $0.99 \%$ ) and constructed protein maps based on a transmittance sensor. Similarly, Maertens et al. ${ }^{13}$ and Long et al. ${ }^{12}$ mounted a reflectance device on a conventional combine and reported successfully measuring wheat protein $(\mathrm{r}=0.55$ to 0.71 and $\mathrm{SEP}=0.56$ to $0.90 \%)$. Corey ${ }^{4}$ compared transmittance and reflectance sensors, with no apparent difference in measurement precision. In Japan, a sampling unit developed by Chosa et al. ${ }^{2}$ for head-feeding combines was used to take wheat samples from site-specific crop management. After drying and husking, samples were measured for protein content by a commercial NIR spectrometer. Mapping was completed to determine the wheat-protein content distribution in the fields ${ }^{3}$. Oido et al. ${ }^{18}$ used a laboratory model to study the possibility of designing a combine-mounted NIR spectrometer. However, there was no protein-content measurement device for head-feeding combines, and no related studies had been performed on rough rice. We therefore developed a protein sensor using NIR for use on a head-feeding combine for rough rice and we will introduce this sensor in this paper.

\section{Examination of combine-mounted NIR spectrometers}

\section{Study of spectroscopic modes}

NIR spectrometers may utilize either transmittance or reflectance, and an investigation of analysis methods for wheat protein found both methods to be equally satisfactory. In the preliminary examination, we investigated both modes as options in the development of our own spectrometer.

We studied transmittance first. In this mode, the stable filling of the measurement cell with rough rice was impossible due to low fluidity and high moisture content, leading to problems of non-repeatability. This gave rise to concerns that a transmittance unit would not provide consistent measurements when mounted on a head-feeding combine (i.e., in an environment of considerable vibration and constantly changing cell-filling states) due to the required highly stable cell-filling conditions. When the cell width was increased sufficiently to allow stable filling, however, it was necessary to increase the light-power intensity or to prolong irradiation in order to allow transmittance through the rice husks and a light intensity sufficiently stable for spectrometric analysis. When these conditions were met, however, rice scorching occurred during measurement. Other difficulties were encountered using the transmittance mode, including the need for a completely darkened cell chamber ${ }^{9}$, and it was concluded that transmittance spectroscopy would pose numerous constraints and thus would not be suitable for the envisioned combine-mounted device.
In our study of the reflectance mode, measurement precision was compared using both NIR reflectance and NIR transmittance spectrometers (Nireco NIRS-6500 (reflectance) and the NIRS-6250 (transmittance)). The samples were dried rough rice (Shizuoka koshihikari) from 2005. As shown in Table 1, the SEP and the coefficient of variation were larger with the transmittance analyzer than the reflectance analyzer. This may be attributed to reduced sample-filling density in reflectance mode, and was considered advantageous for developing the spectrometer. In the reflectance mode, it was possible to obtain an SECV of better than $0.20 \%$ for measurements in the lower wavelength range of 900-1098 $\mathrm{nm}$, although the primary absorption peak of protein was generally reported to be in the longwavelength region of $2170 \mathrm{~nm}^{10}$. If we were to measure around $2170 \mathrm{~nm}$, we would require the use of a $\mathrm{PbS}$ or InGaAs, which is very expensive and requires a low-dust, low-vibration environment ${ }^{19}$. At $1098 \mathrm{~nm}$ and below, it is possible to use an Si-CCD, which is relatively cheap and does not require such a strictly controlled environment and is thus advantageous for the envisioned spectrometer. In light of all of these considerations, we decided to adopt reflectance spectroscopy in developing our combinemounted spectrometer.

Table 1. Comparison of experimental results of protein measurement by two modes

\begin{tabular}{lcccc}
\hline \hline Mode & Device & $\begin{array}{c}\text { Wavelength* } \\
(\mathrm{nm})\end{array}$ & $\begin{array}{c}\text { SECV } \\
(\% \mathrm{DM})\end{array}$ & $\begin{array}{c}\mathrm{CV} \\
(\% \mathrm{DM})\end{array}$ \\
\hline Transmittance NIRS-6250 & $750 \sim 1100$ & 0.25 & 0.127 \\
\hline \multirow{2}{*}{ Reflectance } & \multirow{3}{*}{ NIRS-6500 } & $900 \sim 1098$ & 0.20 & 0.033 \\
& & $1100 \sim 1500$ & 0.20 & 0.042 \\
\hline
\end{tabular}

* We selected the wavelength region that the Si-CCD is able to detect.

\section{Required target accuracy}

The real-time protein content data during harvesting would presumably be utilized for variable field fertilization based on protein maps and classification of brown rice before drying. The range of protein content in brown rice is generally limited to 6 to $12 \% \mathrm{DM}$, and a two- or three-grade classification would fully meet the requirements for determining fertilizer quantities as well as the requirements of the drying facilities. The high precision of commercially available bench-type NIR spectrometers should therefore be unnecessary. In several countries, moreover, wheat trials have generally obtained SEP values in the range of 0.5 $1.0 \%$. In the development of our NIR spectrometers for the analysis of brown rice protein, we selected an SEP value $\leq 0.6 \%$ as the target accuracy; this error is one-tenth or less of the envisioned measurement range. 


\section{Development of an NIR spectrometer for a head- feeding combine}

\section{NIR reflectance spectrometer}

The structure of the developed NIR reflectance spectrometer for mounting on combines is illustrated in Fig. 1. To minimize the influence of combine vibration, the measurement cell filled with rough rice was irradiated from below, and the brown rice protein content was calculated from the reflected light spectrum. A tungsten halogen lamp was used as the light source, with a diffuser attached to prevent exposure to direct light and to obtain uniform irradiation of the rough rice. The spectrometric unit consisted of a post-dispersal spectroscopic analyzer with diffraction grating and an Si-CCD. The measured wavelength region for this unit was 740 to $1140 \mathrm{~nm}$. For the transmittance spectrometry trials, the range was 850 to $1048 \mathrm{~nm}$, which was provided by a commercial NIR transmittance spectrometer (Infratec1241; Foss, Sweden). As seen in Table 1, the preliminary test results indicated that this wavelength was appropriate for estimating the protein content of brown rice. The Si-CCD is a deep-well type with a high $\mathrm{S} / \mathrm{N}$ ratio. The measurement was repeated 50 times, each with an exposure time of $50 \mathrm{~ms}$. The calibration curve was developed in the laboratory.

The timing of the rough rice filling and discharge was controlled by a shutter at the sample inlet to the measurement cell. During discharge, the bottom of the measurement cell was inclined to allow a smooth gravity fall. At measurement onset and at regular intervals during measurement, a color adjustment was performed using a reference white plate.

\section{Developing the calibration curve}

We developed the calibration curve that estimated the brown rice protein from the spectrum of the rough rice. The original spectrum was smoothed using the Savitzky-Golay algorithm with the second derivative. The calibration curve was developed by partial least squares (PLS) regression with full cross-validation. The PLS regression was performed with The Unscrambler ver. 9.6 (CAMO, Norway). A total of 147 rough rice samples of 23 varieties from the BRAIN experimental farm and from agricultural experiment stations in 11 districts of Japan were chosen for the trial measurements in order to provide a range of varieties and growing regions. The brown rice protein was chemically analyzed using the Kjeldahl method on the commission of the Japan Grain Inspection Association.

The second derivatives spectra obtained from the lab examinations are presented in Fig. 2. The protein content of the specimen samples was 6.7 to $10.2 \%$ DM. Differences were clearly observable in the protein-absorption region near $910 \mathrm{~nm}$. The scatter plot is presented in Fig. 3. The

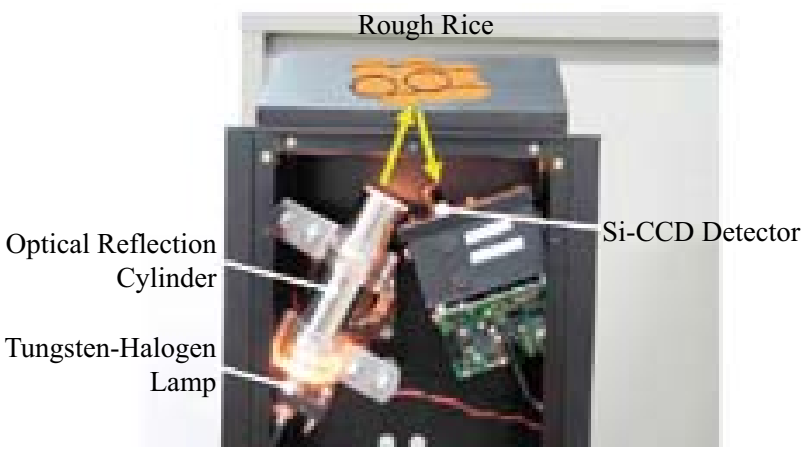

Fig. 1. Internal structure of reflectance NIR sensor

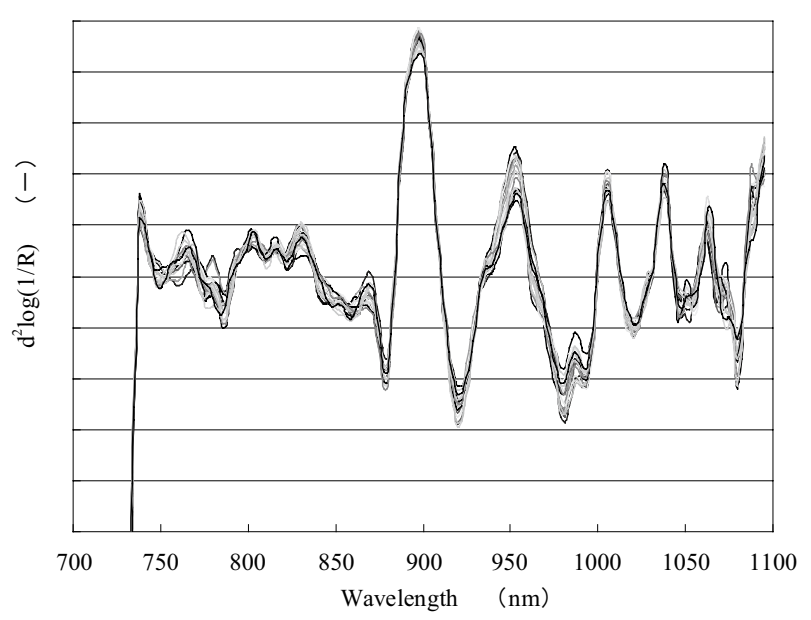

Fig. 2. Second derivative spectra of rough rice

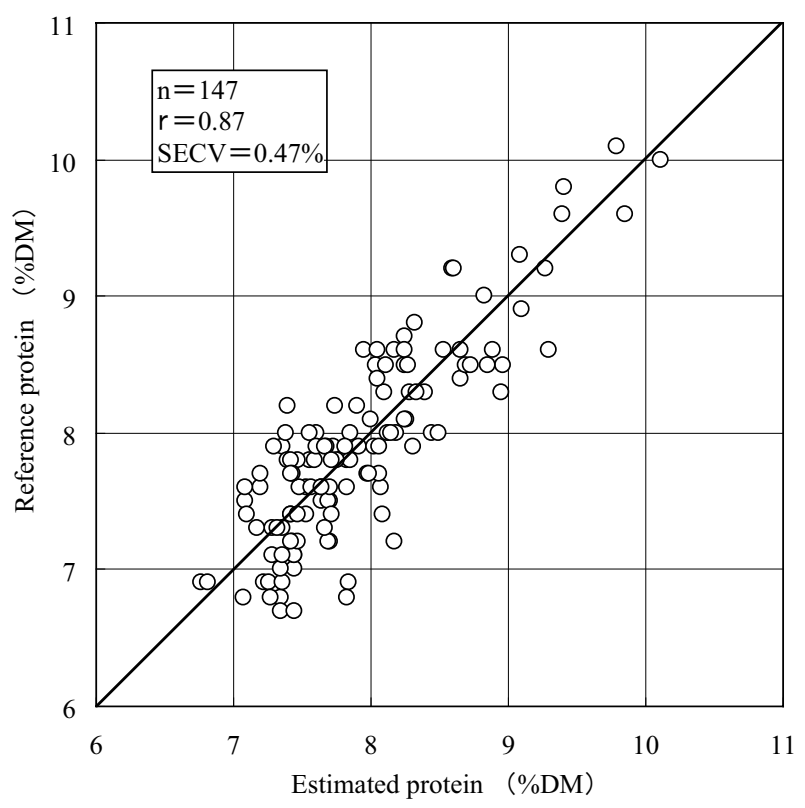

Fig. 3. Evaluation of calibration carve

* Reference protein by chemical analysis using Kjeldahl method

calibration accuracy was $\mathrm{r}=0.87$ and $\mathrm{SECV}=0.47 \%$. 


\section{Combine system}

The NIR reflectance spectrometer mounted on a yieldmonitoring combine (four-row type) consisted of a weight sensor (load cell), a moisture sensor (electric-resistance type), and GPS device shown in Fig. 4, developed in $2003^{15}$. The spectrometer was mounted on the grain tank in a position facilitating discharge of the rough rice from the grain auger into the measurement chamber (Fig. 5). This position was selected in part based on a report by Chosa et al. ${ }^{2}$, which indicated that such positioning enabled uniform sampling on a head-feeding combine. The measurement procedure on the combine was as follows: the measurement chamber was filled with rough rice discharged from the grain auger, the spectra of the rice were measured, and the rice was returned to the grain tank after measurement by opening the shutter. The actual measurement time was 2.5 $\mathrm{s}$, and the measurement cycle was set at $30 \mathrm{~s}$ in accordance with the time required for the rough rice to fill the measurement chamber.

Measured values were stored and monitored by a work-monitoring system developed at BRAIN based on precision agricultural equipment for rice field use, with standard I/O ports, software-enabled GPS-based map control, and specifications for operation on commercial $\mathrm{PCs}^{5}$. Communication between the work-monitoring system and the yield and moisture content measurement units of the yield-monitoring combine and the NIR reflectance spectrometer was performed with an RS-232C interface controlled by a small PC installed in the combine cabin. The system was operated using the PC's touch panel. The weight, moisture, and protein content were displayed in real time while harvesting. For the protein value, the program was modified to enable the measurement to be displayed on-screen. The mean value and standard deviation were calculated for each block in the field and were displayed upon completion of the harvesting operation. The monitor screen during actual operation can be seen in Fig. 6 .

\section{Evaluating the developed system}

Brown rice protein content measurement using the above equipment and the harvesting operation were performed as concurrent processes in fields divided into 27 test blocks. Three of the rice varieties (koshihikari, yumeminori, and asanohikari) were grown in blocks with varying fertilizer amounts in order to obtain different protein contents. The field is on the BRAIN experimental farm located in Kounosu, Saitama Prefecture. The trials were conducted on four different dates: 2 December, 2006, 26 and 28 September, 2007, and 3 October, 2007. The accuracy of the weight and the moisture content is not discussed here ${ }^{6,15}$.

The results of the field examination indicate that brown rice protein content measurement is possible using the

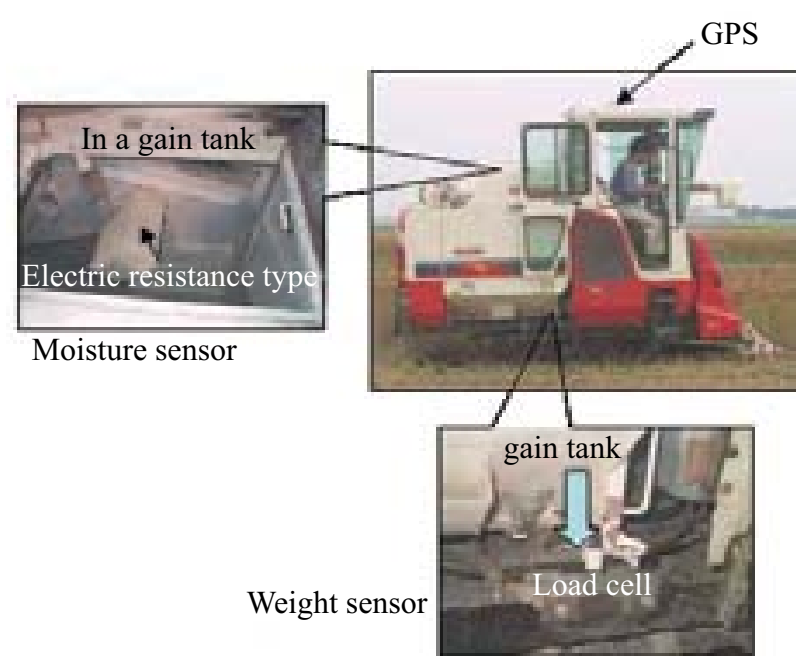

Fig. 4. Outline of the yield monitor combine (Makino et al. ${ }^{15}$ )

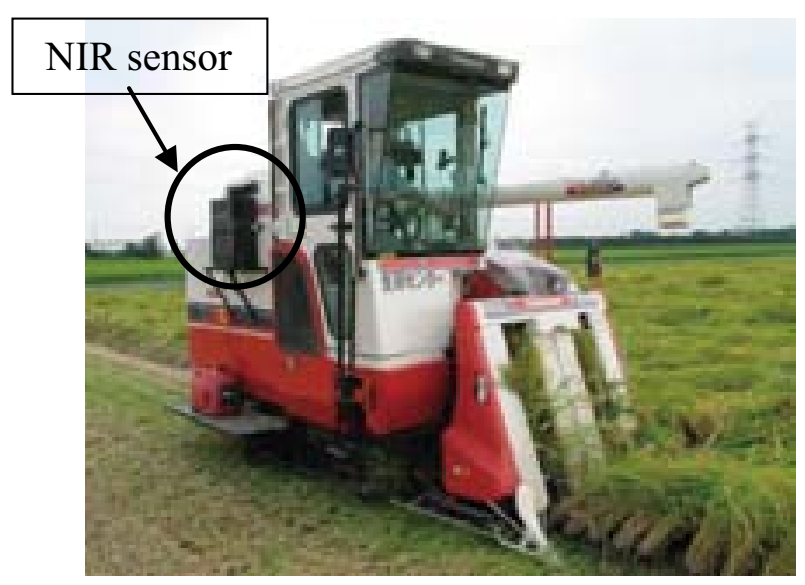

Fig. 5. Developed NIR sensor mounted on the yield monitor combine

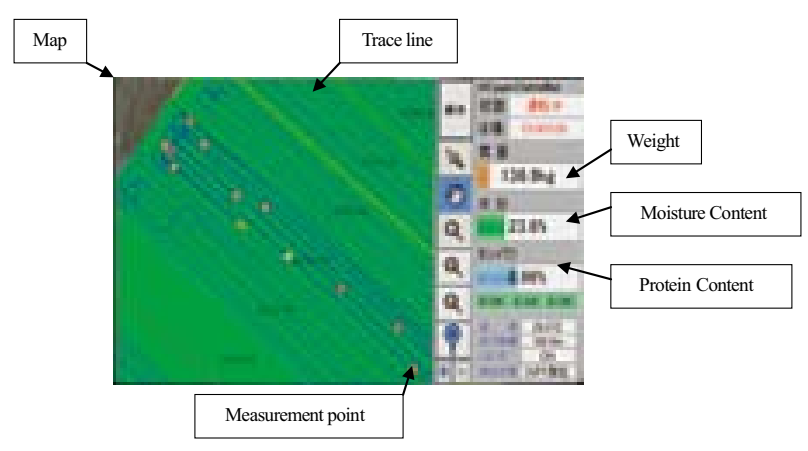

Fig. 6. Screenshot of the monitoring device

developed system despite the harsh environment of the harvesting operation, including high levels of dust and vibration. There were 20 to 30 measurement repetitions per test block (30a), and unbiased sampling in the field was con- 
firmed. No malfunctions occurred during the operation, which covered a total area of about 1 ha, except for a problem in the communication system that prevented data acquisition in one instance. Although no dust adhered to the surfaces of the measuring unit during grain flow, dust and rough rice residues were found after work ended. As the developed protein sensor is an optical device, it requires regular maintenance and careful daily cleaning.

The accuracy of the brown rice protein measurement was $\mathrm{r}=0.65$ and $\mathrm{SEP}=0.22 \%$ (Fig. 7 ). The low correlation coefficient may be an effect of the relatively narrow range of protein content of 7.6 to $8.5 \% \mathrm{DM}$, which is smaller than the range of 6.7 to $10.2 \% \mathrm{DM}$ encountered in the trials for developing the calibration curve. Moreover, as pointed out by Natsuga et al. ${ }^{17}$, moisture content may influence the measurements. In future studies it will be necessary to consider methods of applying moisture content data from the combine to increase precision. In the present trials, the small SEP may also be due in part to the narrow range of the sample mean and deviation, and may thus have resulted in overestimated precision. The actual precision was estimated to be similar to that indicated by the SECV of approximately $0.5 \%$ observed during the laboratory examination. This was the same level of precision as reported for the trials performed by Corey ${ }^{4}$ and meets the development target for measurement precision. It should also be noted, in any event, that rough rice lodging and surface soiling can result in large errors in measurement.

\section{Progress in the future}

As demonstrated by the present study, we succeeded in developing a protein measurement system that can be mounted on a head-feeding combine. The system, however, is not yet at a stage in which it can be readily used at rice production sites. A power supply is necessary, ease of operation must be addressed, and the current maintenance requirements and cost would also hinder its immediate development and adoption for practical use. Moreover, as noted by Natsuga et al. ${ }^{17}$ in relation to their study on quality analysis by NIR, it is generally necessary to generate a robust calibration curve that includes calibration for temper-

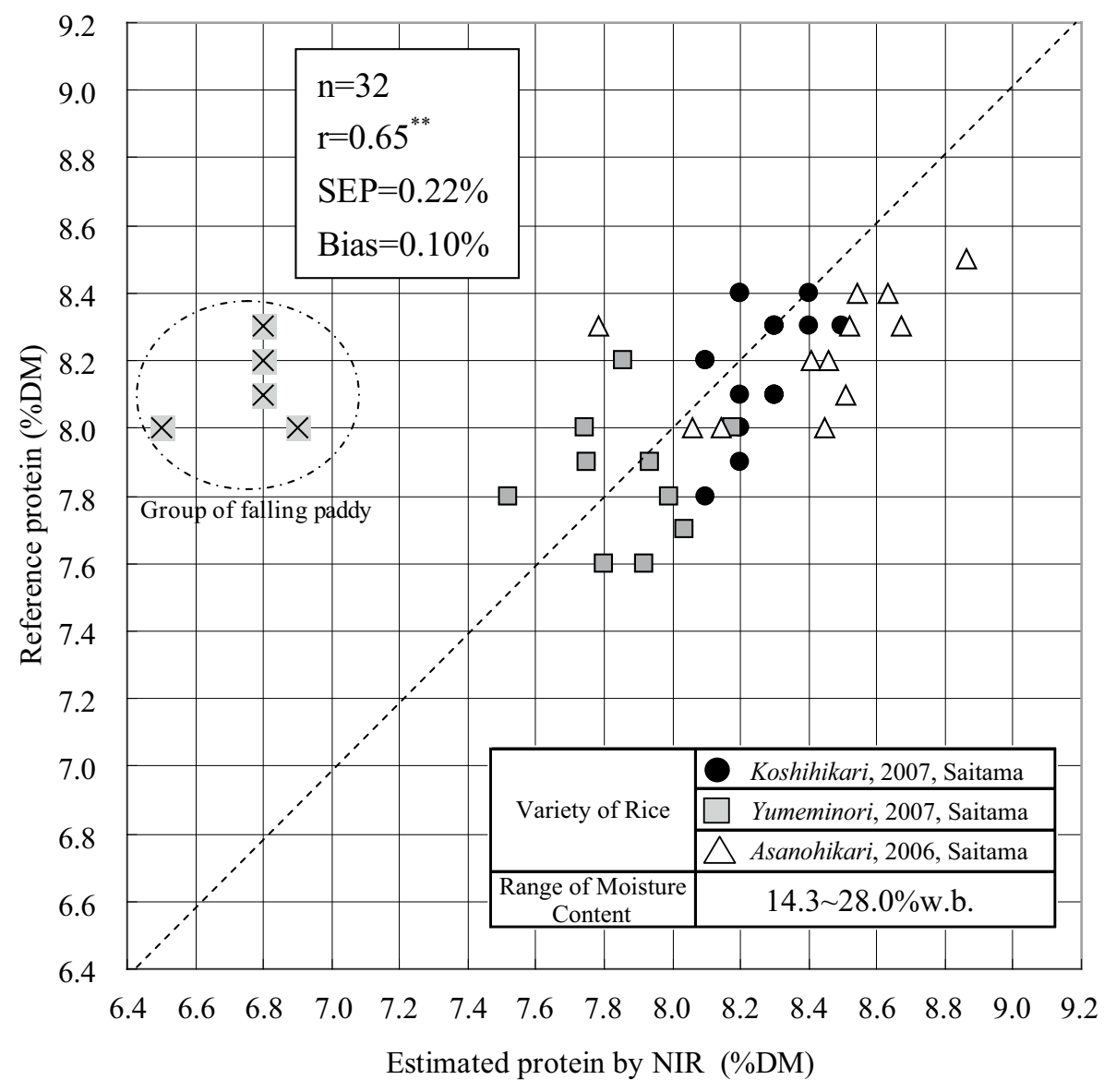

Fig. 7. Protein-content estimation in the field examination

1) n, r, SEP and Bias were calculated except for falling group

2) **Significant Level $1 \%$

* Reference protein by chemical analysis using Kjeldahl method 
ature, product variety, and year of production, and to accumulate data over a period of several years. Future studies will seek to improve and refine the hardware while reducing its size and to both strengthen and refine the calibration curve.

\section{References}

1. Chikubu, S. et al. (1985) Establishment of palatability estimation formula of rice by multiple regression analysis. $J$. Jap. Sci. Starch Sci., 32(1), 51-60 [In Japanese with English summary].

2. Chosa, T. et al. (2006) Yield monitoring system for a headfeeding combine. JARQ, 40(1), 37-43.

3. Chosa, T. et al. (2008) Investigation of yield and quality variability of wheat with conventional harvesting. J. JSAM, 70(1), 92-96 [In Japanese with English summary].

4. Corey, G. M. (2004) Protein mapping spring wheat using a mobile near-infrared sensor and terrain modeling. A Thesis of Montana State Univ., 1-72.

5. Hayashi, K. (2007) GIS base information management system for precision farming. J. JSAM, 69(5), 21-24 [In Japanese].

6. Hidaka, Y. et al. (2009) Development of combine harvester with yield monitoring function (part 4). J. JSAM, 71(4), 6068 [In Japanese with English summary].

7. http://www.nirtech.net/index.php/products/, 2010.4.13.

8. http://www.zeltex.com/accuharvest.html, 2010.4.13.

9. Iwamoto, M., Kawano, S. \& Uozumi, J. (2002) Kinsekigai bunkohou nyumon (Near-Infrared Spectroscopy), Second edition, Saiwai Shobou Co Ltd., Tokyo, pp.40-134 [In Japanese].

10. Kamishikiryo, H., Hasegawa, K. \& Matoba, T. (1991) Stability of $2170 \mathrm{~nm}$ as a key wavelength for protein analysis by infrared spectroscopy. Nippon shokuhin Kougyou gakkai- shi ( J. Food Sci. Technol.), 38(9), 850-857.

11. Long, D.S. \& Rosenthal T. (2005) Evaluation of an on-combine wheat protein analyzer on Montana hard spring wheat. Proc. 5th European Conf. Prec. Aguric., Uppsala, Sweden, 912.

12. Long, D.S. et al. (2008) Measuring grain protein concentration with in-line near infrared reflectance spectroscopy. Agron J., Vol. 100, Issue 2, 247-252.

13. Maertens, K. Reyns, P. \& Baerdemaeker, J. De. (2004) Online measurement of grain quality with NIR technology. Trans. ASAE, 47(4), 1135-1140.

14. Makino, E. et al. (2005) Quality of rice in Japan (part 2). $J$. JSAM, 67(4), 166-172 [In Japanese with English summary].

15. Makino, E. et al. (2007) Development of combine harvester with yield monitoring function (Part1). J. JSAM, 69(4), 7988 [In Japanese with English summary].

16. NAME Co. Ltd. (2006). Seitaijouhou konnbainn ni kannsuru ni-zu chyousa (Investigation Report of Farmer's Concern about NIR Combine). NAME Co. Ltd., Tokyo, 1-43 [In Japanese].

17. Natsuga, M., Kawamura, S. \& Itoh, K. (1994) Factors affecting in determining constituent content of grain by NIR spectroscopy (part 1). J. JSAM, 56(2), 41-48 [In Japanese with English summary].

18. Oido, N., Iida, M. \& Umeda, M. (2004) A combine-mounted NIR spectroscopy-based sensor for single rice kernel protein content measurement. Proc. of Automation Technology for Off-Road Equipment, Kyoto, Japan, 380-386.

19. Okura, T. (2006) Non-destructive quality check by near infrared spectroscopy. ITE Technical Report, Vol.30, No.10, 1318.

20. Taylor, J. et al. (2005) Monitoring wheat protein content on harvester. Proc. 5th European Conf. Prec. Aguric., Uppsala, Sweden, 369-375. 